\title{
Adjunctive treatment for cognitive impairment in patients with chronic schizophrenia: a double-blind, placebo-controlled study
}

This article was published in the following Dove Press journal:

Neuropsychiatric Disease and Treatment

I 4 July 2014

Number of times this article has been viewed

\author{
Weiwei Zhu',2,* \\ Zhanchou Zhang ${ }^{1, *}$ \\ Jingfeng $\mathrm{Qi}^{1}$ \\ Fang $\mathrm{Liu}^{3}$ \\ Jindong Chen ${ }^{1,4,5}$ \\ Jingping Zhao ${ }^{1,4,5}$ \\ Xiaofeng Guo 1,4,5
}

'Institute of Mental Health, Second Xiangya Hospital, Central South

University, ${ }^{2}$ Brain Hospital of Hunan

Province, Changsha, ${ }^{3}$ First Affiliated

Hospital of Kunming Medical

University, Kunming, ${ }^{4}$ National

Technology Institute of Psychiatry,

${ }^{5}$ Key Laboratory of Psychiatry and

Mental Health of Hunan Province,

Changsha, People's Republic of China

*These authors contributed equally to this work
Correspondence: Xiaofeng Guo Institute of Mental Health, Second Xiangya Hospital, Central South University, I 39 Renmin Middle Road, Changsha, 4100II, Hunan, People's Republic of China

$\mathrm{Tel}+8673$ I 85554052

Fax +86 73। 85554052

Email xfguocsu@163.com

\begin{abstract}
Cognitive impairment is closely related to real-life functioning in patients with schizophrenia. The aim of the present study was to evaluate the effects of adjunctive treatment with donepezil on cognition in patients with chronic schizophrenia. This was a 12-week, double-blind, randomized, placebo-controlled study of donepezil as an adjunct to antipsychotic drug therapy in patients with chronic stable schizophrenia. Sixty-one subjects were randomized to receive donepezil $5 \mathrm{mg} /$ day $(\mathrm{n}=31)$ and/or placebo $(\mathrm{n}=30)$. A nine-test neuropsychological assessment battery was administered at baseline and at the end of the study. At the 12-week end point, the donepezil group showed significant improvements in the Wechsler Memory Scale Third Edition Spatial Span, Brief Visuospatial Memory Test total recall and delayed recall, TrailMaking Test Part A, and Category Fluency Test-animal naming (all $P \leq 0.018$ ). Compared with placebo, donepezil was associated with significant improvement in several cognitive domains, including working memory, speed of information processing, and visual learning and memory $(P \leq 0.008)$. The results of the present study suggest that adjunctive use of donepezil is beneficial for improving cognitive function in patients with schizophrenia.
\end{abstract}

Keywords: schizophrenia, cognitive function, donepezil

\section{Introduction}

Patients with schizophrenia have significant cognitive impairment, especially in the domains of attention, executive function, memory, verbal skills, and processing speed. ${ }^{1,2}$ This impairment is a major determinant of their real-life functioning, so is an important treatment target. ${ }^{3}$ The effects of antipsychotic medications on cognition in schizophrenia appear to be minimal. ${ }^{3}$ Recent studies examining novel adjunctive treatments have yielded some encouraging results. ${ }^{4,5}$

Transmission of acetylcholine in the central nervous system plays a vital role in cognitive function, specifically in attention and memory. ${ }^{6}$ Modulation of the alpha-7 nicotinic acetylcholine receptor has been considered a potential treatment target in Alzheimer's disease and schizophrenia. ${ }^{7}$ Acetylcholinesterase inhibitors, including donepezil, rivastigmine, and galantamine, have shown some cognitive benefit in Alzheimer's disease and related dementias. ${ }^{8}$

Several studies have investigated the effects of acetylcholinesterase inhibitors on cognition in schizophrenia. ${ }^{5,9-12}$ Although a recent meta-analysis does not support the use of acetylcholinesterase inhibitors for mild cognitive impairment, ${ }^{13}$ several previous studies in schizophrenia spectrum disorders have reported significant cognitive improvement using donepezil as adjunctive therapy.,12 Many factors, including cigarette smoking, stage of cognitive impairment, and duration of illness, may influence the effects 
of acetylcholinesterase inhibitors on cognition. ${ }^{14,15}$ Selecting appropriate measurement tools is also important to assess the effects of donepezil on cognition, given that cognitive function includes many different domains in schizophrenia. ${ }^{1,2}$

Here we present a 12-week, randomized, double-blind, placebo-controlled trial (ClinicalTrials.gov identifier NCT01490567) examining the effect of donepezil as an adjunct to atypical antipsychotic (risperidone or olanzapine) therapy on cognitive impairment in Chinese patients with chronic schizophrenia. Risperidone and olanzapine are commonly used new-generation antipsychotic medications in the People's Republic of China. Unlike the previous research, participants in our study had chronic schizophrenia, a duration of illness of less than 10 years, excluded ex-smokers or current smokers, and included an extensive cognitive battery.

\section{Materials and methods}

\section{Participants}

All participants were recruited from the Second Xiangya Hospital of Central South University between June 2011 and November 2012. Consenting patients aged 18-40 years were eligible for the study if they met the DSM-IV (Diagnostic and Statistical Manual of Mental Disorders, Fourth Edition) criteria for schizophrenia determined by the Structured Clinical Interview for DSM-IV. Patients had to be clinically stable (Positive and Negative Syndrome Scale [PANSS] ${ }^{16}$ total scores $\leq 60) ;{ }^{17}$ have a duration of illness of more than 2 years but less than 10 years; and be treated with risperidone or olanzapine at a stable dose for at least 4 weeks. We excluded patients with mental retardation or severe organic brain syndrome; those diagnosed with a serious or unstable medical condition; those who were pregnant or breastfeeding; those receiving concomitant anticholinergic drugs; ex-smokers or current smokers; patients treated with electroconvulsive therapy within the 6 months prior to screening; those who had made suicidal attempts or displayed ideation or violent behavior within the last 12 months; and those who had participated in other therapy programs.

\section{Study design}

The study was designed as a 12-week, double-blind, placebocontrolled, randomized trial. The study protocol was approved by the ethics committee of the Second Xiangya Hospital of Central South University, and was carried out in accordance with the Guideline for Good Clinical Practice and the Declaration of Helsinki. Every patient or their legal guardian provided written informed consent before enrollment.

After screening, patients were randomized to receive donepezil $5 \mathrm{mg} /$ day or placebo in addition to their antipsychotic treatment. Doses of antipsychotic medications remained fixed throughout the study. Benzodiazepines for insomnia and propranolol for akathisia or tachycardia were permitted as needed during the study. Patients who received benzodiazepines needed to wait for 48 hours prior to cognitive testing.

\section{Neuropsychological assessments}

A nine-test neuropsychological battery was administered at baseline and at the end of the study. These nine tests were grouped into seven cognitive domains. Working memory was evaluated using the Wechsler Memory Scale Third Edition Spatial Span (WMS-III SST). ${ }^{18}$ Verbal memory was tested using the Hopkins Verbal Learning Test-Revised. ${ }^{19}$ Visual memory was assessed with the Brief Visuospatial Memory Test-Revised. ${ }^{20}$ The tests for processing speed included the Trail-Making Test Part A (TMT-A), ${ }^{21}$ Brief Assessment of Cognition in Schizophrenia-symbol coding, ${ }^{22}$ and Category Fluency Test-animal naming. ${ }^{23}$ Attention was evaluated with Continuous Performance Test-Identical Pairs (CPT-IP). ${ }^{24}$ In addition, the Wisconsin Card Sorting Test ${ }^{25}$ and Stroop Color and Word Test ${ }^{26}$ were used to assess reasoning and problem-solving, and inhibition and interference control functions, respectively.

To calculate cognitive domain scores, all test measures were first converted to standardized $z$ scores by setting the sample mean of each measure at baseline to zero and the standard deviation to 1 . For domains with more than one test, summary scores were determined by calculating the mean of the $z$ scores for the measures that comprised the domain, then converting the mean to a $z$ score with a mean of zero and a standard deviation of one. ${ }^{27}$

\section{Clinical and safety assessments}

The severity of psychopathology was assessed using the PANSS. ${ }^{16}$ The Clinical Global Impressions (CGI) scale item for severity of illness was used to assess global changes. ${ }^{28}$ Depressive symptoms were evaluated using the Calgary Depression Scale for Schizophrenia (CDSS). ${ }^{29}$ The Simpson-Angus Rating Scale ${ }^{30}$ and the Abnormal Involuntary Movement Scale ${ }^{31}$ were used to assess extrapyramidal symptoms and dyskinetic movements, respectively. The PANSS, CDSS, CGI, Simpson-Angus Rating Scale, and Abnormal Involuntary Movement Scale ratings were administered monthly. Safety evaluations included physical examinations, electrocardiography, vital signs, and adverse events. A complete blood count and urinalysis were performed at baseline and at the end of the study. Intraclass correlation coefficients for these instruments ranged from 0.82 to 0.88 . All raters were blinded to treatment assignment. 


\section{Statistical analysis}

All analyses were conducted using the Statistical Package for Social Sciences version 17.0 software (SPSS Inc, Chicago, IL, USA). The alpha level for testing the statistical significance of effects was $P=0.05$ unless otherwise indicated. Data analysis was based on the intent-to-treat population, including all eligible patients with at least one follow-up assessment. For missing data, the last observation carried forward was used for analysis. Between-group comparisons of demographic and clinical characteristics at baseline were performed using the Student's $t$-test for continuous variables and the $\chi^{2}$ test or Fisher's Exact test for categorical variables. Between-group comparisons for cognitive scores at baseline were performed using analysis of covariance controlling for age and education.

The primary outcome measure was the change in cognitive scores from baseline to 12 weeks. Within-group comparisons of continuous variables between baseline and end point were examined using the paired-samples $t$-test. Between-group comparisons in cognitive function at end point were performed using analysis of covariance, controlling for baseline, age, and education. Bonferroni corrections were used to set the cut-off for statistical significance at $0.004(0.05 / 14)$ and $0.008(0.05 / 7)$ for multiple comparisons in 14 cognitive scores and in seven cognitive domain scores, respectively. Effect size (changes in cognitive domain from baseline to week 12) was calculated using Cohen's formula. ${ }^{32}$ In addition, the $\chi^{2}$ test or Fisher's Exact test was used to compare between-group differences in adverse events.

\section{Results \\ Baseline characteristics and follow-up}

A total of 61 patients were enrolled in the study, and $52 \mathrm{com}-$ pleted cognitive function testing at baseline and at 12 weeks follow-up (Figure 1). The demographic and clinical characteristics of the 61 patients are shown in Table 1. There were no significant differences between the two groups for age, sex, education, psychopathology scores, or duration of illness (all $P \geq 0.083$, Table 1).

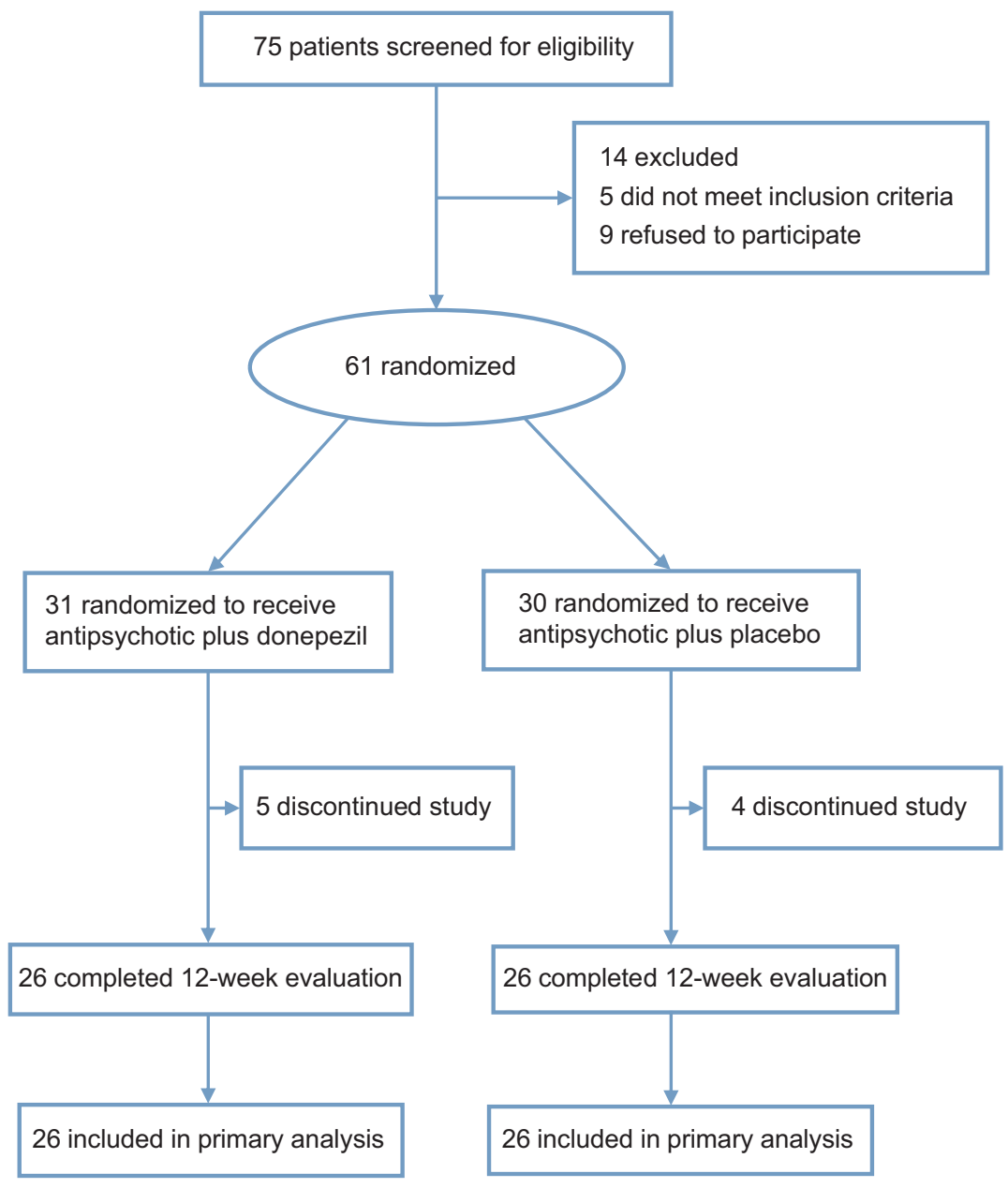

Figure I Flow chart of participation in the study. 
Table I Demographic and clinical characteristics of patients who received donepezil or placebo

\begin{tabular}{|c|c|c|c|c|}
\hline Characteristics & Donepezil (n=3I) & Placebo $(n=30)$ & $F I \chi^{2}$ & $P$-value \\
\hline Age (years) & $24.71(5.91)$ & $25.90(4.42)$ & 0.790 & 0.378 \\
\hline Sex, n (\%) & & & 0.455 & 0.500 \\
\hline Male & $14(45.16)$ & II (36.67) & & \\
\hline Female & $17(54.84)$ & $19(63.33)$ & & \\
\hline Education (years) & $11.65(1.91)$ & $10.23(2.65)$ & 0.488 & 0.487 \\
\hline Duration of illness (years) & $4.83(2.48)$ & $5.12(2.49)$ & 0.212 & 0.647 \\
\hline \multirow{2}{*}{\multicolumn{5}{|c|}{$\begin{array}{l}\text { Dose of antipsychotic agents } \\
(\mathrm{mg} / \text { day)/patients (total number) }\end{array}$}} \\
\hline & & & & \\
\hline Risperidone & $4.07(1.21) / 15$ & $4.03(1.20) / 15$ & 0.006 & 0.940 \\
\hline Olanzapine & $16.25(6.45) / 16$ & $17.33(6.5 \mathrm{I}) / 15$ & 0.216 & 0.645 \\
\hline Positive psychiatric family history, n (\%) & $8(25.8 \mathrm{I})$ & $7(23.33)$ & 0.500 & 0.823 \\
\hline PANSS total score & $54.94(8.92)$ & $52.37(9.16)$ & 1.231 & 0.272 \\
\hline CGI severity score & $3.87(0.8 \mathrm{I})$ & $3.53(0.68)$ & 3.112 & 0.083 \\
\hline CDSS total score & $3.55(1.96)$ & $3.00(1.75)$ & I.487 & 0.227 \\
\hline
\end{tabular}

Notes: $\chi^{2}$ for categorical variables and analysis of variance for continuous variables; mean (standard deviation) unless otherwise indicated.

Abbreviations: PANSS, Positive and Negative Syndrome Scale; CDSS, Calgary Depression Scale for Schizophrenia; CGI, Clinical Global Impressions scale.

\section{Effects of treatment on cognitive function}

When compared with baseline, significant improvements were found in the WMS-III SST, TMT-A, Category Fluency Test-animal naming, and Brief Visuospatial Memory Test-Revised total recall and delayed recall at end point in the donepezil group (all $P \leq 0.018$, Table 2).

At week 12, cognitive function scores show significant differences in WMS-III SST, TMT-A, Category Fluency Test-animal naming, and Brief Visuospatial Memory TestRevised total recall and delayed recall between the two groups (all $P \leq 0.001$, Table 2 ).

Figure 2 shows the effect size of changes in domain scores after 12 weeks of treatment with donepezil. Significant effects of donepezil were found in working memory, speed of processing, and visual learning and memory (all $P \leq 0.008$ ).

\section{Effects of treatment on clinical efficacy and safety outcomes}

Compared with baseline, significant improvements were found in PANSS scores and CDSS total scores at end point (all $t \geq 2.302$, all $P \leq 0.030$ ). There were no significant differences in PANSS total score or CDSS total score between two groups at end point (all $F \leq 3.314$, all $P \geq 0.075$ ). No significant differences were found in rates of adverse events between the two groups ( $P \geq 0.492$, Table 3$)$.

\section{Discussion}

This placebo-controlled, double-blind study investigated the efficacy and tolerability of donepezil as adjunctive therapy for cognitive impairment in Chinese patients with chronic schizophrenia. The study indicates that donepezil was safe and well tolerated, and effective as an add-on treatment to improve cognitive function in this patient population.

Our data show that at the 12-week end point, the donepezil group had significant improvements in the WMS-III SST, Brief Visuospatial Memory Test total recall and delayed recall, TMT-A, and Category Fluency Test-animal naming. Effect size analysis showed that the donepezil group experienced moderate improvement in working memory, speed of processing, and visual learning and memory. The difference between the largest effect size for the cognitive domain score $(0.54)$ and the smaller effect size $(\leq 0.27)$ is $\geq 0.27$, or about one third of a standard deviation (1). If we assume that the smaller effect sizes reflect only practice effects, then the difference $(\geq 0.27)$ could represent an actual treatment effect, albeit a "small" effect with low clinical significance. ${ }^{32}$

A number of previous studies have investigated the cognitive effects of acetylcholinesterase inhibitors in schizophrenia. ${ }^{5,-12}$ Some trials suggested that donepezil and other acetylcholinesterase inhibitors may have potential benefits for cognitive impairment in schizophrenia, ${ }^{5,12}$ but a large multicenter study by Keefe et al failed to demonstrate any cognitive effects of donepezil in patients with schizophrenia or schizoaffective disorder. ${ }^{11}$ Most patients were smokers or ex-smokers, and the mean duration of schizophrenia was long (18 years) in their study. A previous study suggested that cognitive impairment is progressive during the course of the illness; $; 3$ therefore, some of the study participants may not have responded well to donepezil in the study by Keefe et al. The evidence for an effect of cigarette smoking on cognitive deficits in schizophrenia is mixed. Several studies have showed that nicotine improves the cognitive deficits, ${ }^{34,35}$ but others have 
Table 2 Neuropsychological test scores of patients with schizophrenia who received donepezil or placebo

\begin{tabular}{|c|c|c|c|c|c|}
\hline & \multirow[t]{2}{*}{ Time } & \multirow[t]{2}{*}{ Donepezil group $(n=26)$} & \multirow[t]{2}{*}{ Placebo group $(n=26)$} & \multicolumn{2}{|c|}{ Between-group comparison } \\
\hline & & & & $\boldsymbol{F}$ & $P$-value \\
\hline \multirow[t]{2}{*}{ CPT-IP } & Baseline & $2.15(0.5 \mathrm{I})$ & $2.10(0.58)$ & 0.092 & 0.763 \\
\hline & 12 weeks & $2.25(0.72)$ & $2.30(0.63)$ & 0.016 & 0.901 \\
\hline \multirow[t]{2}{*}{ WMS-III SST } & Baseline & $15.00(3.26)$ & $14.92(3.38)$ & 0.042 & 0.838 \\
\hline & 12 weeks & $16.92(1.53)^{* *}$ & $14.96(2.35)$ & 16.694 & $<0.001$ \\
\hline \multicolumn{6}{|l|}{ WCST } \\
\hline \multirow[t]{2}{*}{ Perseverative errors } & Baseline & I5.88 (5.94) & I 3.27 (5.84) & 3.521 & 0.067 \\
\hline & 12 weeks & $15.19(8.72)$ & I2.88 (8.58) & 1.604 & 0.212 \\
\hline \multirow[t]{2}{*}{ Categories completed } & Baseline & $2.88(1.56)$ & $3.23(1.31)$ & 0.463 & 0.499 \\
\hline & 12 weeks & $3.04(1.46)$ & $3.35(1.47)$ & 3.063 & 0.086 \\
\hline \multirow[t]{2}{*}{ TMT-A } & Baseline & $45.56(15.02)$ & $45.15(13.00)$ & 0.011 & 0.918 \\
\hline & 12 weeks & $38.63(11.28) * *$ & $45.01(12.34)$ & 11.446 & 0.001 \\
\hline \multirow[t]{2}{*}{ BACS SC } & Baseline & $44.12(11.54)$ & $43.62(9.98)$ & 0.028 & 0.868 \\
\hline & 12 weeks & $46.58(9.92)$ & 43.31 (7.76) & 2.683 & 0.108 \\
\hline \multirow[t]{2}{*}{ CFT animal naming } & Baseline & I5.23 (4.0I) & I5.54 (4.13) & 0.074 & 0.786 \\
\hline & 12 weeks & $17.35(3.78) * *$ & $|4.8|(3.20)$ & 11.644 & 0.001 \\
\hline \multicolumn{6}{|l|}{ BVMT-R } \\
\hline \multirow[t]{2}{*}{ Total recall } & Baseline & $21.65(8.05)$ & I9.88 (8.5I) & 0.593 & 0.445 \\
\hline & 12 weeks & $25.54(6.90) * *$ & $17.92(6.04)$ & 33.898 & $<0.001$ \\
\hline \multirow[t]{2}{*}{ Delayed recall } & Baseline & $8.73(3.21)$ & $8.04(3.38)$ & 1.098 & 0.300 \\
\hline & 12 weeks & $10.58(2.18)^{*}$ & $7.69(3.12)$ & 22.148 & $<0.001$ \\
\hline \multicolumn{6}{|l|}{ HVLT-R } \\
\hline \multirow[t]{2}{*}{ Total recall } & Baseline & $21.50(6.29)$ & $20.62(6.40)$ & 0.253 & 0.617 \\
\hline & 12 weeks & $21.88(5.40)$ & $19.38(4.89)$ & 3.045 & 0.088 \\
\hline \multirow[t]{2}{*}{ Delayed recall } & Baseline & $7.58(2.56)$ & $6.62(2.89)$ & 1.613 & 0.210 \\
\hline & 12 weeks & 8.04 (2.79) & $6.31(2.36)$ & 2.406 & 0.128 \\
\hline \multicolumn{6}{|l|}{ Stroop Task } \\
\hline \multirow[t]{2}{*}{ Word } & Baseline & 104.04 (19.49) & $107.19(23.94)$ & 0.073 & 0.788 \\
\hline & 12 weeks & $106.69(14.24)$ & $109.38(18.70)$ & 0.316 & 0.577 \\
\hline \multirow[t]{2}{*}{ Color } & Baseline & $66.08(15.75)$ & $69.46(18.34)$ & 0.063 & 0.803 \\
\hline & 12 weeks & $68.12(15.51)$ & $68.58(14.52)$ & 0.012 & 0.912 \\
\hline \multirow[t]{2}{*}{ Color-Word } & Baseline & $43.46(12.07)$ & $41.5(10.73)$ & 1.106 & 0.298 \\
\hline & 12 weeks & 47.77 (I4.62) & 45.35 (I2.60) & 1.063 & 0.308 \\
\hline
\end{tabular}

Notes: Within-group differences were analyzed using the paired-samples $t$-test. $* P<0.05, * * P<0.01$; between-group comparisons were analyzed using analysis of covariance controlling for baseline, age, and education.

Abbreviations: CPT-IP, Continuous Performance Test-Identical Pairs; WMS-III SST, Wechsler Memory Scale-Third Edition Spatial Span; WCST, Wisconsin Card Sorting Test; TMT-A, Trail-Making Test Part A; BACS SC, Brief Assessment of Cognition in Schizophrenia Symbol Coding test; CFT, Category Fluency test; BVMT-R, Brief Visuospatial Memory Test-Revised; HVLT-R, Hopkins Verbal Learning Test-Revised.

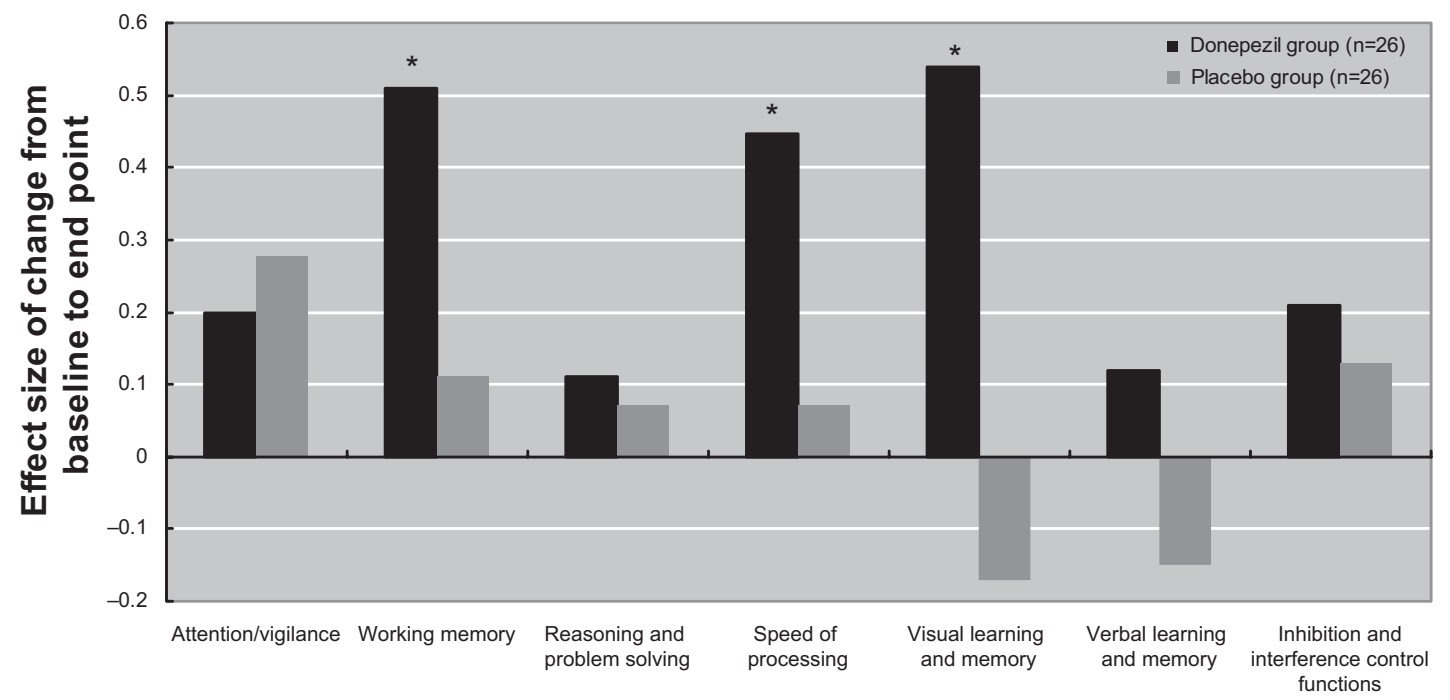

Figure 2 Effect size of change in domain scores after 12 weeks of treatment with donepezil or placebo in patients with schizophrenia. Notes: Between-group comparisons were analyzed using analysis of covariance controlling for baseline, age, and education. $* p<0.008$. 
Table 3 Safety measures of patients with schizophrenia who received donepezil or placebo

\begin{tabular}{|c|c|c|c|c|}
\hline Adverse events, n (\%) & Donepezil $(n=31)$ & Placebo $(n=30)$ & $\chi^{2} /$ Fisher's exact test & $P$-value \\
\hline Extrapyramidal symptoms & $10(32.29)$ & $9(30.00)$ & 0.036 & 0.849 \\
\hline Dry mouth & $2(6.45)$ & I (3.33) & - & 1.000 \\
\hline Insomnia and agitation & $2(6.45)$ & $2(6.67)$ & - & 1.000 \\
\hline Dizziness & I (3.23) & $0(0)$ & - & 0.492 \\
\hline Nausea $^{a}$ & I (3.23) & I (3.33) & - & 1.000 \\
\hline Menstrual irregularities & I (5.88) & $2(10.53)$ & - & 0.612 \\
\hline $\begin{array}{l}\text { Weight gain }>7 \% \text { (from } \\
\text { baseline to last observation) }\end{array}$ & $5(16.12)$ & $4(13.33)$ & 0.095 & 0.758 \\
\hline
\end{tabular}

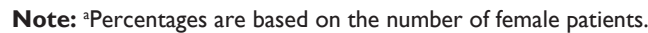

found little or no association between smoking and cognitive deficits in schizophrenia. ${ }^{36}$ Cigarette smoking can desensitize nicotine receptors in patients with schizophrenia, who do not show the normal upregulation following chronic nicotine use. ${ }^{37}$ This might have prevented donepezil reaching its full potential with regard to cognitive enhancement in patients with schizophrenia who smoked, in the study by Keefe et al. ${ }^{11}$

The cholinergic system has been implicated in the regulation of attention, memory, processing speed, and sensory gating, ${ }^{38}$ all of which are impaired in schizophrenia. Autoradiography studies have shown alterations in the density and expression of acetylcholine receptors in the brains of patients with schizophrenia. ${ }^{39,40}$ Post mortem studies have also demonstrated changes in muscarinic and nicotinic receptor availability or expression. ${ }^{41,42}$ The activity of choline acetyltransferase, a biomarker of cholinergic neuronal function, in the parietal cortex of patients with schizophrenia was shown to be negatively correlated with the severity of cognitive impairment. ${ }^{43}$ These studies suggest that schizophrenia is associated with multiple abnormalities of the cholinergic system. Thus, cholinesterase inhibitors may be useful in the treatment of cognitive impairment in patients with schizophrenia.

Donepezil had limited effects on psychotic symptoms. There was no difference in effects on symptoms of psychopathology between the two groups in our study. Donepezil was also well tolerated. The incidence of adverse events was similarly low in both groups.

There are several potential limitations to our study. First, the dose of $5 \mathrm{mg} /$ day is lower than that used in previous similar research. ${ }^{44}$ Donepezil is administered once daily in a dose range of 5-10 $\mathrm{mg}$ for Alzheimer's disease, but in some Asian countries, the recommended dose is lower. ${ }^{8}$ Second, our patients were treated with donepezil for 12 weeks, which might be too short to demonstrate the effect of donepezil on cognitive function. Donepezil significantly improves cognitive function in Alzheimer's dementia for up to 6 months. ${ }^{8}$ Higher doses or a longer treatment duration may have yielded greater cognitive improvement. Third, the sample size was small. Future randomized controlled investigations with a larger sample size are warranted. Finally, our study excluded smokers, so the generalizability of the findings might be limited. However, the rate of cigarette smoking in Chinese patients with schizophrenia is $13.9 \%$, so is lower than the rates reported in most of the previous studies. ${ }^{45}$

In summary, the results of this double-blind, placebocontrolled study suggest a potential cognitive benefit from adjunctive use of donepezil in Chinese patients with schizophrenia.

\section{Acknowledgments}

We are very grateful to Xiaoduo Fan from UMass Memorial Medical Center, University of Massachusetts Medical School, Worcester, MA, USA, for assistance in revising our manuscript. This research was supported by grants from the National Natural Science Foundation of China (30900485, 81270019) and the National R\&D Special Fund for the Health Profession (201002003).

\section{Disclosure}

The authors report that they have no direct conflict of interest or grant support that is directly related to the content of the study.

\section{References}

1. Green MF, Kern RS, Braff DJ, Mintz J. Neurocognitive deficits and functional outcome in schizophrenia: are we measuring the "right stuff"? Schizophr Bull. 2000;26(1):119-136.

2. Goldberg TE, Goldman RS, Burdick KE, et al. Cognitive improvement after treatment with second-generation antipsychotic medications in first-episode schizophrenia: is it a practice effect? Arch Gen Psychiatry. 2007;64(10):1115-1122.

3. Keefe RS, Harvey PD. Cognitive impairment in schizophrenia. Handb Exp Pharmacol. 2012;213:11-37.

4. Preskorn SH, Gawryl M, Dgetluck N, Palfreyman M, Bauer LO, Hilt DC. Normalizing effects of EVP-6124, an alpha-7 nicotinic partial agonist, on event-related potentials and cognition: a proof of concept, randomized trial in patients with schizophrenia. J Psychiatr Pract. 2014;20(1):12-24.

5. Ribeiz SR, Bassitt DP, Arrais JA, Avila R, Steffens DC, Bottino CM. Cholinesterase inhibitors as adjunctive therapy in patients with schizophrenia and schizoaffective disorder: a review and meta-analysis of the literature. CNS Drugs. 2010;24(4):303-317. 
6. Amenta F, Tayebati SK. Pathways of acetylcholine synthesis, transport and release as targets for treatment of adult-onset cognitive dysfunction. Curr Med Chem. 2008;15(5):488-498.

7. Pohanka M. Alpha-7 Nicotinic acetylcholine receptor is a target in pharmacology and toxicology. Int J Mol Sci. 2012;13(2):2219-2238.

8. Di Santo SG, Prinelli F, Adorni F, Caltagirone C, Musicco M. A metaanalysis of the efficacy of donepezil, rivastigmine, galantamine, and memantine in relation to severity of Alzheimer's disease. J Alzheimers Dis. 2013;35(2):349-361.

9. Buchanan RW, Conley RR, Dickinson D, et al. Galantamine for the treatment of cognitive impairments in people with schizophrenia. Am J Psychiatry. 2008;165(1):82-89.

10. Lindenmayer JP, Khan A. Galantamine augmentation of long-acting injectable risperidone for cognitive impairments in chronic schizophrenia. Schizophr Res. 2011;125(2-3):267-277.

11. Keefe RS, Malhotra AK, Meltzer HY, et al. Efficacy and safety of donepezil in patients with schizophrenia or schizoaffective disorder: significant placebo/practice effects in a 12-week, randomized, doubleblind, placebo-controlled trial. Neuropsychopharmacology. 2008;33(6): 1217-1228.

12. Erickson SK, Schwarzkopf SB, Palumbo D, Badgley-Fleeman J, Smirnow AM, Light GA. Efficacy and tolerability of low-dose donepezil in schizophrenia. Clin Neuropharmacol. 2005;28(4):179-184.

13. Tricco AC, Soobiah C, Berliner S, et al. Efficacy and safety of cognitive enhancers for patients with mild cognitive impairment: a systematic review and meta-analysis. CMAJ. 2013;185(16):1393-1401.

14. Kumari V1, Postma P. Nicotine use in schizophrenia: the self medication hypotheses. Neurosci Biobehav Rev. 2005;29(6):1021-1034.

15. Thakurathi N, Vincenzi B, Henderson DC. Assessing the prospect of donepezil in improving cognitive impairment in patients with schizophrenia. Expert Opin Investig Drugs. 2013;22(2):259-265.

16. Kay SR, Fiszbein A, Opler LA. The Positive and Negative Syndrome Scale (PANSS) for schizophrenia. Schizophr Bull. 1987;13(2):261-276.

17. Guo X, Zhai J, Liu Z, et al. Effect of antipsychotic medication alone vs combined with psychosocial intervention on outcomes of early-stage schizophrenia: a randomized, 1-year study. Arch Gen Psychiatry. 2010;67(9):895-904.

18. Wechsler D. WMS-R: Wechsler Memory Scale-Revised: Manual. San Antonio, TX, USA: Psychological Corporation; 1987.

19. Brandt J, Benedict RHB. Hopkins Verbal Learning Test-Revised: Professional Manual. Lutz, FL, USA: Psychological Assessment Resources; 2001 .

20. Benedict R. Brief Visuospatial Memory Test-Revised: Professional Manual. Odessa, FL, USA: Psychological Assessment Resources; 1997.

21. Reitan RM, Wolfson D. The Halstead-Reitan Neuropsychological Test Battery: Theory and Clinical Interpretation. 2nd ed. South Tucson, AZ, USA: Neuropsychology Press; 1997.

22. Keefe RS. Brief Assessment of Cognition in Schizophrenia (BACS) Manual-A. Version 2.1. Durham, NC, USA: Duke University Medical Center; 1999.

23. Spreen Q, Strauss E. A Compendium of Neuropsychological Tests: Administration, Norms, and Commentary. 2nd ed. New York, NY, USA: Oxford University Press; 1998.

24. Cornblatt BA, Risch NJ, Faris G, Friedman D, Erlenmeyer-Kimling L. The Continuous Performance Test, identical pairs version (CPT-IP): I. New findings about sustained attention in normal families. Psychiatry Res.1988;26(2):223-238.

Neuropsychiatric Disease and Treatment

\section{Publish your work in this journal}

Neuropsychiatric Disease and Treatment is an international, peerreviewed journal of clinical therapeutics and pharmacology focusing on concise rapid reporting of clinical or pre-clinical studies on a range of neuropsychiatric and neurological disorders. This journal is indexed on PubMed Central, the 'PsycINFO' database and CAS,
25. Heaton RK. Wisconsin Card Sorting Test Manual: Revised and Expanded. Lutz, FL, USA: Psychological Assessment Resources; 1993.

26. Golden CJ. Stroop Color and Word Test: A Manual for Clinical Experimental Uses. Wood Dale, IL, USA: Stoelting Co; 1978.

27. Keefe RS, Sweeney JA, Gu H, et al. Effects of olanzapine, quetiapine, and risperidone on neurocognitive function in early psychosis: a randomized, double-blind 52-week comparison. Am J Psychiatry. 2007; 164(7):1061-1071.

28. Guy W. ECDEU Assessment Manual for Psychopharmacology. Rockville, MD, USA: US Department of Health, Education, and Welfare Public Health Service, Alcohol, Drug Abuse, and Mental Health Administration; 1976.

29. Addington D, Addington J, Maticka-Tyndale E. Assessing depression in schizophrenia: the Calgary Depression Scale. Br J Psychiatry Suppl. 1993;22:39-44

30. Simpson GM, Angus JW. A rating scale for extrapyramidal side effects. Acta Psychiatr Scand Suppl. 1970;212:11-19.

31. Lane RD, Glazer WM, Hansen TE, Berman WH, Kramer SI. Assessment of tardive dyskinesia using the Abnormal Involuntary Movement Scale. J Nerv Ment Dis. 1985;173(6):353-357.

32. Cohen J. A power primer. Psychol Bull. 1992;112(1):155-159.

33. Bilder RM, Goldman RS, Robinson D, et al. Neuropsychology of first episode schizophrenia: initial characterization and clinical correlates. Am J Psychiatry. 2000;157(4):549-559.

34. Krishnadas R, Jauhar S, Telfer S, Shivashankar S, McCreadie RG. Nicotine dependence and illness severity in schizophrenia. Br J Psychiatry. 2012;201(4):306-312.

35. Winterer G. Why do patients with schizophrenia smoke? Curr Opin Psychiatry. 2010;23(2):112-119.

36. Barnes M, Lawford BR, Burton SC, et al. Smoking and schizophrenia: is symptom profile related to smoking and which antipsychotic medication is of benefit in reducing cigarette use? Aust NZJ Psychiatry. 2006; 40(6-7):575-580.

37. Kumari V, Postma P. Nicotine use in schizophrenia: the self medication hypotheses. Neurosci Biobehav Rev. 2005;29(6):1021-1034.

38. Furey ML, Pietrini P, Haxby JV. Cholinergic enhancement and increased selectivity of perceptual processing during working memory. Science. 2000;290(5500):2315-2319.

39. Crook JM, Tomaskovic-Crook E, Copolov DL, Dean B. Decreased muscarinic receptor binding in subjects with schizophrenia: a study of the human hippocampal formation. Biol Psychiatry. 2000;48(5):381-388.

40. Breese CR, Lee MJ, Adams CE, et al. Abnormal regulation of high affinity nicotinic receptors in subjects with schizophrenia. Neuropsychopharmacology. 2000;23(4):351-364.

41. Freedman R, Hall M, Adler LE, Leonard S. Evidence in postmortem brain tissue for decreased numbers of hippocampal nicotinic receptors in schizophrenia. Biol Psychiatry. 1995;38(1):22-33.

42. Guan ZZ, Zhang X, Blennow K, Nordberg A. Decreased protein level of nicotinic receptor alpha-7 subunit in the frontal cortex from schizophrenic brain. Neuroreport. 1999;10(8):1779-1782.

43. Powchik P, Davidson M, Haroutunian V, et al. Postmortem studies in schizophrenia. Schizophr Bull. 1998;24(2):325-341.

44. Tsuno N. Donepezil in the treatment of patients with Alzheimer's disease. Expert Rev Neurother. 2009;9(5):591-598.

45. Wang CY, Xiang YT, Weng YZ, et al. Cigarette smoking in patients with schizophrenia in China: prospective, multicentre study. Aust NZ J Psychiatry. 2010;44(5):456-462.

\section{Dovepress}

and is the official journal of The International Neuropsychiatric Association (INA). The manuscript management system is completely online and includes a very quick and fair peer-review system, which is all easy to use. Visit http://www.dovepress.com/testimonials.php to read real quotes from published authors. 